\title{
Transcriptomic analysis of the oleaginous yeast Lipomyces starkeyi during lipid accumulation on enzymatically treated corn stover hydrolysate
}

Kyle R. Pomraning ${ }^{1 *}\left(\mathbb{D}\right.$, James R. Collett ${ }^{1}$, Joonhoon Kim ${ }^{1,2}$, Ellen A. Panisko ${ }^{1}$, David E. Culley ${ }^{1}, Z^{2} y u$ Dai ${ }^{1}$, Shuang Deng ${ }^{1}$, Beth A. Hofstad ${ }^{1}$, Mark G. Butcher ${ }^{1}$ and Jon K. Magnuson ${ }^{1,2^{*}}$

\begin{abstract}
Background: Efficient and economically viable production of biofuels from lignocellulosic biomass is dependent on mechanical and chemical pretreatment and enzymatic hydrolysis of plant material. These processing steps yield simple sugars as well as plant-derived and process-added organic acids, sugar-derived dehydration products, aldehydes, phenolics and other compounds that inhibit the growth of many microorganisms. Lipomyces starkeyi is an oleaginous yeast capable of robust growth on a variety of sugars and lipid accumulation on pretreated lignocellulosic substrates making it attractive as an industrial producer of biofuels. Here, we examined gene expression during batch growth and lipid accumulation in a 20-L bioreactor with either a blend of pure glucose and xylose or pretreated corn stover (PCS) that had been enzymatically hydrolyzed as the carbon sources.

Results: We monitored sugar and ammonium utilization as well as biomass accumulation and found that growth of L. starkeyi is inhibited with PCS hydrolysate as the carbon source. Both acetic acid and furfural are present at concentrations toxic to L. starkeyi in PCS hydrolysate. We quantified gene expression at seven time-points for each carbon source during batch growth and found that gene expression is similar at physiologically equivalent points. Analysis of promoter regions revealed that gene expression during the transition to lipid accumulation is regulated by carbon and nitrogen catabolite repression, regardless of carbon source and is associated with decreased expression of the translation machinery and suppression of the cell cycle. We identified 73 differentially expressed genes during growth phase in the bioreactor that may be involved in detoxification of corn stover hydrolysate.

Conclusions: Growth of L. starkeyi is inhibited by compounds present in PCS hydrolysate. Here, we monitored key metabolites to establish physiologically equivalent comparisons during a batch bioreactor run comparing PCS hydrolysate and purified sugars. L. starkeyi's response to PCS hydrolysate is primarily at the beginning of the run during growth phase when inhibitory compounds are presumably at their highest concentration and inducing the general detoxification response by L. starkeyi. Differentially expressed genes identified herein during growth phase will aid in the improvement of industrial strains capable of robust growth on substrates containing various growth inhibitory compounds.
\end{abstract}

Keywords: Lipomyces starkeyi, Oleaginous, Yeast, Bioreactor, Biofuel, Corn stover, PCS, Inhibitors, Transcriptome

*Correspondence: Kyle.Pomraning@pnnl.gov; Jon.Magnuson@pnnl.gov

1 Pacific Northwest National Laboratory, Richland, WA, USA

Full list of author information is available at the end of the article 


\section{Background}

The finite and decreasing supply of petroleum available for human utilization has prompted the development of sustainable methods to produce hydrocarbons. Processes to convert lignocellulosic biomass into simple sugars that can be fed to robust microorganisms to produce biofuels are an attractive route to achieve this. Oleaginous fungi capable of producing high quantities of lipids can be used to convert lignocellulosic biomass into biodiesel or hydrocarbon fuel-blending agents utilizable within the petrochemical industry infrastructure. Oleaginous yeasts in particular from the genera Lipomyces, Rhodosporidium, and Yarrowia have proven to be robust lipid accumulators that can be readily engineered for improvement of titer, rate, and yield as well as production of synthetic lipid-derived compounds [1-3].

Rapid conversion of lignocellulosic biomass into biofuels requires that the plant material be physically, chemically, and/or enzymatically broken down to release simple sugars. A wide variety of methods are available to achieve this and result in a spectrum of chemicals derived from the plant biomass, dependent on the pretreatment conditions, along with the simple sugars [4-6]. Dilute acid pretreatment followed by enzymatic digestion was one of the earliest successful strategies for production of simple sugars from lignocellulosic biomass $[7,8]$ and remains relevant for commercial production of biofuels [9-11]. The process is rapid and efficient but yields sugars containing growth and conversion inhibitors such as acetic acid, cinnamic acids, furfural, hydroxymethylfurfural, and phenolic compounds [6, 12-14]. Recent efforts have been made to engineer and evolve bioconversion organisms such as Saccharomyces cerevisiae [10, 15, 16], Bacillus coagulans [11], Zymomonas mobilis [17], Acinetobacter baylyi [18], Caldicellulosiruptor bescii [19], and Rhodococcus opacus [20] among others for improved growth in the presence of these inhibitory compounds. However, a number of fungi capable of robust growth in the presence of pretreatment derived inhibitors have been identified [21, 22]. Lipomyces starkeyi stands out as an oleaginous yeast [23] capable of growth on a wide range of carbon and nitrogen sources and pretreated feedstocks [24-27] in addition to being genetically tractable [28-31].

Here, we applied a systematic approach to characterize the response of $L$. starkeyi to the plethora of compounds that are present in pretreated corn stover enzymatic hydrolysate (PCS) in addition to the primary carbohydrates glucose and xylose. L. starkeyi was grown in a bioreactor in batch mode for production of lipids with all variables held constant with the exception of the carbon source. Online monitoring of biologically relevant parameters and nutrient concentrations was used to sample the bioreactor at physiologically equivalent timepoints (e.g., prior to and after depletion of specific nutrients during batch cultivation) and assay gene expression by RNA sequencing. This is the first thorough analysis of the response to PCS performed in oleaginous yeast. We found that comparing growth on PCS and clean sugars at equivalent physiological states during a batch lipid accumulation run, rather than at equivalent time-points, greatly expanded our understanding of the response to PCS in L. starkeyi by eliminating biases attributable to differences in growth phase and concentration of extracellular carbon sources and other nutrients.

\section{Materials and methods}

\section{Chemicals, growth media and yeast strains}

All chemicals and reagents were purchased from SigmaAldrich (St. Louis, MO) unless otherwise noted. L. starkeyi strain NRRL Y-11558 was obtained from American Type Tissue Culture (ATCC ${ }^{\circledR}$ 64135; Manassas, VA) and was used for all experiments in this study. L. starkeyi was maintained on YPD plates ( $1 \%$ yeast extract, $1 \%$ peptone, $2 \%$ glucose, $2 \%$ agar) at $28{ }^{\circ} \mathrm{C}$. Frozen stocks were maintained at $-80{ }^{\circ} \mathrm{C}$ in $15 \%$ glycerol. For bioreactor experiments, L. starkeyi was pre-grown from glycerol stocks in $50-\mathrm{mL}$ YPD broth in $250-\mathrm{mL}$ shake flasks at $30{ }^{\circ} \mathrm{C}$ and $200 \mathrm{rpm}$. Saccharified dilute acid pretreated corn stover (PCS; lot CH131104) was provided as a slurry with $60.2 \%$ moisture by Dan Schell of the National Renewable Energy Laboratory (NREL; Golden, CO), along with the compositional analysis of the PCS shown in Table 1.

Table 1 Composition of pretreated corn stover used in this study

\begin{tabular}{|c|c|c|c|c|c|c|c|c|c|}
\hline \multicolumn{10}{|c|}{ Solids composition (\% w/w dry basis) } \\
\hline Ash & Protein & Lignin & Glucan & Xylan & Galactan & Arabinan & Mannan & Acetate & \\
\hline 2.4 & 1.8 & 27.9 & 60.7 & 3.8 & ND & 0.7 & ND & 0.3 & \\
\hline \multicolumn{10}{|c|}{ Composition of liquor fraction (g/L) } \\
\hline Lignin & Cellobiose & Glucose & Xylose & Galactose & Arabinose & Fructose & Acetate & HMF & Furfural \\
\hline 9.94 & 2.66 & 21.38 & 157.74 & 9.81 & 19.48 & ND & 13.2 & 0.5 & 4.08 \\
\hline
\end{tabular}


PCS medium used in the experiments was prepared by suspending $3 \mathrm{~kg}$ of the PCS slurry into $\sim 20 \mathrm{~L}$ of distilled water. The diluted slurry was passed through a coarse screen mesh to remove rocks and other large debris, and then hydrolyzed with CTEC2 and HTEC2 enzymes (Novozymes; Franklinton, NC) at $50{ }^{\circ} \mathrm{C}$ for $96 \mathrm{~h}$. Prior to enzymatic hydrolysis, the $\mathrm{pH}$ of the diluted PCS had been raised to 5.0 via the addition of $5-\mathrm{M} \mathrm{KOH}$. The hydrolyzed PCS was harvested from the bioreactor and then passed through a CEPA continuous centrifuge spinning at 20,000 RPM to remove fine-suspended lignin and other particles. Enzymatic hydrolysis of PCS yielded $54.0 \mathrm{~g} / \mathrm{L}$ glucose, $3.3 \mathrm{~g} / \mathrm{L}$ acetic acid, $0.092 \mathrm{~g} / \mathrm{L}$ hydroxymethylfurfural, and $1.25 \mathrm{~g} / \mathrm{L}$ furfural. A portion of the clarified supernatant was diluted with distilled water to prepare MMPCS media with a targeted glucose concentration of $18.5 \mathrm{~g} / \mathrm{L}$ with $100 \%$ of the sugars in the medium coming from the hydrolyzed PCS. The MMPCS medium was supplemented with $1.5 \mathrm{~g} / \mathrm{L} \mathrm{KH}_{2} \mathrm{PO}_{4}, 0.62 \mathrm{~g} / \mathrm{L} \mathrm{NH}_{4} \mathrm{Cl}$, $0.5 \mathrm{~g} / \mathrm{L} \mathrm{KCl}, 0.5 \mathrm{~g} / \mathrm{L} \mathrm{MgSO}{ }_{4} \cdot 7 \mathrm{H}_{2} \mathrm{O}$, and $1 \mathrm{mg} / \mathrm{L}$ each of biotin, pyridoxine, thiamine, riboflavin, para-aminobenzoic acid, and nicotinic acids, along with $1 \mathrm{~mL} / \mathrm{L}$ of a $1000 \times$ trace elements solution containing $2.25 \mathrm{~g} / \mathrm{L}$ $\mathrm{ZnSO}_{4} \cdot 7 \mathrm{H}_{2} \mathrm{O}, 11 \mathrm{~g} / \mathrm{L} \mathrm{H}_{3} \mathrm{BO}_{3}, 5 \mathrm{~g} / \mathrm{L} \mathrm{MnCl}_{2} \cdot 4 \mathrm{H}_{2} \mathrm{O}, 5 \mathrm{~g} / \mathrm{L}$ $\mathrm{FeSO}_{4} \cdot 7 \mathrm{H}_{2} \mathrm{O}, 1.7 \mathrm{~g} / \mathrm{L} \mathrm{CoCl}_{2} \cdot 6 \mathrm{H}_{2} \mathrm{O}, 1.6 \mathrm{~g} / \mathrm{L} \mathrm{CuSO}_{4} \cdot 5 \mathrm{H}_{2} \mathrm{O}$, $0.085 \mathrm{~g} / \mathrm{L} \mathrm{Na}_{2} \mathrm{MoO}_{4} \cdot 2 \mathrm{H}_{2} \mathrm{O}$, and $5 \mathrm{~g} / \mathrm{L} \mathrm{Na}{ }_{4}$ EDTA. The initial concentration of potentially inhibitory compounds in this medium after dilution is $1.14 \mathrm{~g} / \mathrm{L}$ acetic acid, $0.032 \mathrm{~g} / \mathrm{L}$ hydroxymethylfurfural, and $0.43 \mathrm{~g} / \mathrm{L}$ furfural. A synthetic medium identified as MMGX was prepared with identical sugar concentrations and nutrient supplements to the MMPCS medium $(18.5 \mathrm{~g} / \mathrm{L}$ glucose, $8.7 \mathrm{~g} / \mathrm{L}$ xylose, $1.5 \mathrm{~g} / \mathrm{L} \mathrm{KH}_{2} \mathrm{PO}_{4}, 0.62 \mathrm{~g} / \mathrm{L} \mathrm{NH} \mathrm{NH}_{4} \mathrm{Cl}, 0.5 \mathrm{~g} / \mathrm{L} \mathrm{KCl}$, $0.5 \mathrm{~g} / \mathrm{L} \mathrm{MgSO}_{4} \cdot 7 \mathrm{H}_{2} \mathrm{O}$, and $1 \mathrm{mg} / \mathrm{L}$ each of biotin, pyridoxine, thiamine, riboflavin, para-aminobenzoic acid, and nicotinic acids, along with $1 \mathrm{~mL} / \mathrm{L}$ of a $1000 \times$ trace elements solution containing $2.25 \mathrm{~g} / \mathrm{L} \mathrm{ZnSO}_{4} \cdot 7 \mathrm{H}_{2} \mathrm{O}$, $11 \mathrm{~g} / \mathrm{L} \mathrm{H}_{3} \mathrm{BO}_{3}, 5 \mathrm{~g} / \mathrm{L} \mathrm{MnCl} \cdot 4 \mathrm{H}_{2} \mathrm{O}, 5 \mathrm{~g} / \mathrm{L} \mathrm{FeSO}_{4} \cdot 7 \mathrm{H}_{2} \mathrm{O}$, $1.7 \mathrm{~g} / \mathrm{L} \mathrm{CoCl} \mathrm{Co}_{2} \cdot 6 \mathrm{H}_{2} \mathrm{O}, 1.6 \mathrm{~g} / \mathrm{L} \quad \mathrm{CuSO}_{4} \cdot 5 \mathrm{H}_{2} 0,0.085 \mathrm{~g} / \mathrm{L}$ $\mathrm{Na}_{2} \mathrm{MoO}_{4} \cdot 2 \mathrm{H}_{2} \mathrm{O}$, and $5 \mathrm{~g} / \mathrm{L} \mathrm{Na}_{4}$ EDTA) but with the sugars provided by the addition of purified glucose and xylose powders instead of the PCS slurry.

\section{Bioreactor cultivation of L. starkeyi}

Submerged stirred tank cultivations of L. starkeyi cells were performed using either MMPCS or MMGX growth medium in $20 \mathrm{~L}$ of media within a 30-L Sartorius Biostat$\mathrm{C}$ bioreactor, under the following identical conditions: the bioreactor was charged with medium and sterilized at $121^{\circ} \mathrm{C}$ for $30 \mathrm{~min}$. The medium $\mathrm{pH}$ was adjusted to 6.0 and then maintained at a minimum of 5.5 via the automated addition of $5-\mathrm{M} \mathrm{KOH}$. The temperature was maintained at $30{ }^{\circ} \mathrm{C}$, the stirring speed was set at a constant rate of $600 \mathrm{RPM}$, and the dissolved oxygen concentration was maintained at $50 \%$ via the automated control of sparging air flow, which varied between 1 and 30 LPM during the course of the experiments. The bioreactor was inoculated with washed $L$. starkeyi cells (that had been grown in shake flasks as described above) to achieve a concentration of $10^{6}$ cells $/ \mathrm{mL}$ in the bioreactor vessel. Samples of $50-100 \mathrm{~mL}$ in volume were taken from the bioreactor broth at regular intervals during the experiments. $1 \mathrm{~mL}$ of the broth was immediately dispensed into each of two cryotubes and immediate-frozen in liquid nitrogen for later transcriptomic analysis. Another $4 \mathrm{~mL}$ of the broth was passed through a $0.2 \mu \mathrm{m}$ filter and then frozen at $-20{ }^{\circ} \mathrm{C}$ for later analysis of sugar, nutrient, and metabolite concentrations. The remaining broth was centrifuged at $1825 \times g$ to pellet the yeast cells, which were then washed in distilled water and centrifuged again. The supernatant was discarded and the pelleted cells were then stored at $-80^{\circ} \mathrm{C}$. The pelleted cells were later lyophilized and their dry cell mass was measured gravimetrically. Aliquots of the dry cell mass were taken for measurement of intracellular lipid concentration, as described below.

\section{Bioreactor broth analysis}

Changes in the concentrations of sugar substrates during the course of the bioreactor and shake flask cultivations were determined via high-pressure liquid chromatography (HPLC) analysis. Samples of the centrifuged culture supernatant were thawed to room temperature, vigorously mixed, and then serially diluted. From each dilution, a $10-\mu \mathrm{L}$ injection of sample into an Agilent 1200 HPLC system equipped with a BEH Amide column (Waters XBridge, $130 \AA, 3.5 \mu \mathrm{m}, 4.6 \mathrm{~mm} \times 250 \mathrm{~mm}$ ) and a guard column (Waters XBridge, $130 \AA ., 3.5 \mu \mathrm{m}$, $4.6 \mathrm{~mm} \times 20 \mathrm{~mm}$ ) that were maintained at $30{ }^{\circ} \mathrm{C}$. An isocratic solution of $40 \%$ acetone, $40 \%$ acetonitrile, $0.1 \%$ ammonium hydroxide at $0.6 \mathrm{~mL} / \mathrm{min}$ was used to elute samples from the column into an evaporative light scattering detector (ELSD, Alltech ELSD 2000). The ELSD settings were as follows: tube temperature, $63{ }^{\circ} \mathrm{C}$; nebulizer gas flowrate, $1.5 \mathrm{~mL} / \mathrm{min}$; and gain, 8 . The ELSD signal was converted from analog to digital using a dualchannel interface (Agilent 35900E) for integration with the HPLC software. Calibration was performed on sugars dissolved in water using the peak area of the HPLC chromatogram. For each sugar, the data were analyzed at five different weight percent levels with quadruplicate measurements for each level in a blocked randomized design. Triplicate measurements were performed on each sample in a blocked randomized design with triplicate measurements of check standards at three different weight percent levels (low, medium and high) to validate instrument 
performance over the course of the analyses. Preliminary measurements of sugar substrate concentrations and measurements of bioreactor broth ammonia concentrations were made using a YSI 2950 Biochemistry Analyzer (Yellow Springs Instruments).

\section{Intracellular lipid quantification}

From each previously frozen culture sample, $100 \mathrm{mg}$ of dried cells was taken and then mixed with an internal standard consisting of $40 \mathrm{mg}$ of a tridecanoic acid (C13:0) in $0.5 \mathrm{~mL}$ of methanol, along with $0.35 \mathrm{~mL}$ of $10-\mathrm{N} \mathrm{KOH}$ and another $2.65 \mathrm{~mL}$ of methanol. This mixture was incubated in a capped 50-mL Pyrex glass tube in a water bath shaker at $55^{\circ} \mathrm{C}$ for $1.5 \mathrm{~h}$. After incubation, the tube was cooled under cold tap water. $0.29 \mathrm{~mL}$ of $24 \mathrm{~N} \mathrm{H}_{2} \mathrm{SO}_{4}$ was then added to the tube, which was inverted for mixing multiple times until a white $\mathrm{K}_{2} \mathrm{SO}_{4}$ precipitate began to form. To complete FAME synthesis, the tube was again incubated at $55^{\circ} \mathrm{C}$ for $1.5 \mathrm{~h}$ while shaking. The capped tube was again cooled under tap water. The FAMEs were extracted from the cell mixture via the addition of $10 \mathrm{~mL}$ of hexane to the tube, which was agitated on a Vortex mixer for $5 \mathrm{~min}$, and then centrifuged at $2750 \times g$ for $5 \mathrm{~min}$. Aliquots of the supernatant were then submitted in triplicate for gas chromatography $(\mathrm{GC})$ analysis.

\section{Transcriptomic sample preparation and analysis}

RNA was extracted from samples using a Maxwell 16 LEV Plant RNA kit (Promega, Madison, WI) and sequenced on an Illumina platform. Sequences were mapped to the L. starkeyi NRRL-11557 genome [24] to predict transcription start sites and quantify expression. Clustering analyses were performed in $\mathrm{R}$ and expression level of genes quantified with featureCounts [32] and converted into reads per kilobase million (RPKM) (Additional file 1). Samples belonging to growth, transition, or stationary phase for each bioreactor run were treated as replicates to identify genes significantly differentially expressed in MMPCS versus MMGX using DESeq2 (adjusted $p$ value $<0.01$ and $\log _{2}$ fold-change $>1$ ) [33]. Gene ontology analysis was performed with FunRich [34]. Metabolic modeling and biochemical pathway visualization utilized Cytoscape3 [35]. Promoter enrichment analysis was performed using DREME [36], Tomtom [37].

\section{Results}

Toxicity of inhibitory compounds present in pretreated corn stover

Production of biofuels such as green diesel from alternative and renewable resources is desirable to reduce the carbon footprint of liquid hydrocarbon transportation fuels. Here, we investigated the use of PCS as a source of carbon (primarily in the form of glucose and xylose) for the production of lipid-derived biofuels. Economically viable processes to produce carbon accessible in the form of sugar monomers from cellulosic biomass typically result in extraction or generation of inhibitory compounds. In the case of PCS, these include small organic acids, lignin-derived compounds, and sugar dehydration products, such as, furfural, and hydroxymethylfurfural. We assessed the presence and concentration of inhibitory compounds in raw PCS lot CH131104 (Table 1), and examined the effect of these compounds on growth of $L$. starkeyi by spiking them individually into MMGX medium along with a small initial population of cells and assessing biomass production in shake flasks after 3 and 7 days. We found that $L$. starkeyi was able to grow in up to $0.2 \mathrm{~g} / \mathrm{L}$ furfural, $0.63 \mathrm{~g} / \mathrm{L}$ hydroxymethylfurfural, and $0.25 \mathrm{~g} / \mathrm{L}$ acetic acid (Fig. 1). While furfural, hydroxymethylfurfural, and acetic acid are all toxic to $L$. starkeyi, only

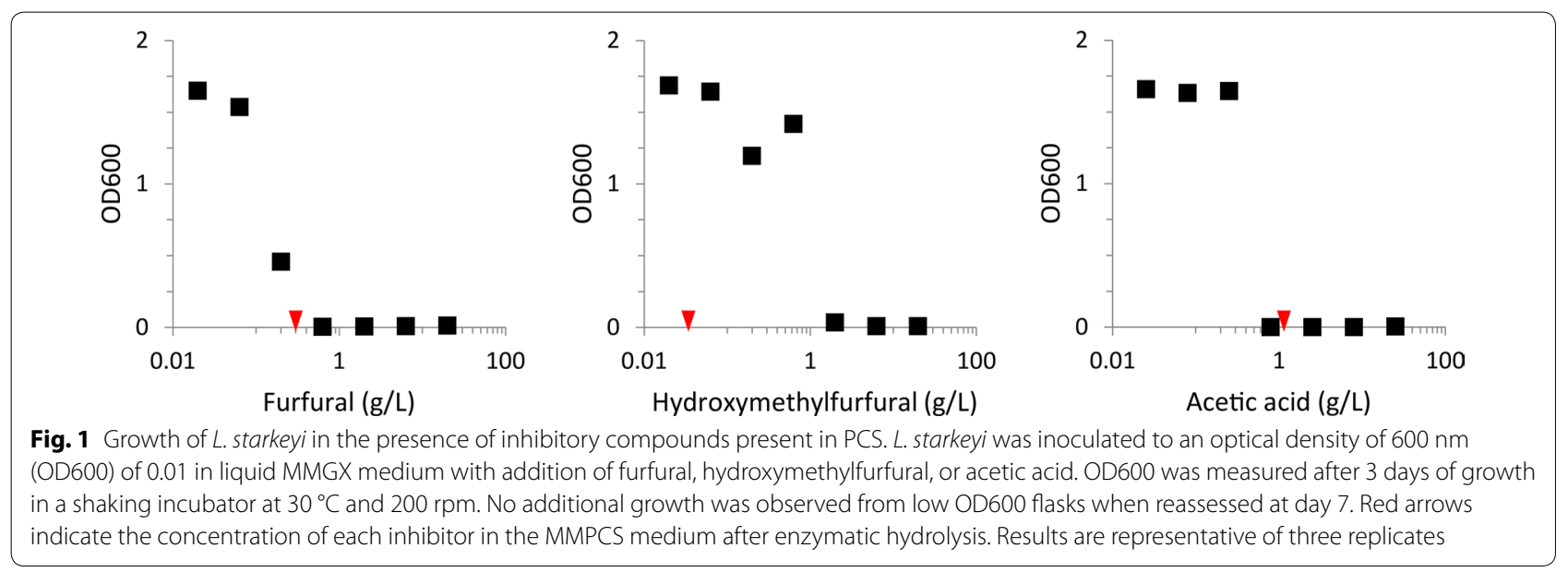


furfural and acetic acid are present at potentially toxic concentrations in PCS.

\section{Identification of the response to PCS using a batch lipid accumulation strategy}

We designed a batch bioreactor cultivation strategy to assess the effect of inhibitory compounds present in PCS on nitrogen limitation-induced lipid production by the oleaginous yeast $L$. starkeyi. We utilized a minimal medium (MM) formulated with nitrogen (ammonium chloride) as the growth-limiting nutrient (Fig. 2) and cultivated the yeast in a 20-L bioreactor with either PCS (MMPCS) or an equivalent amount of glucose and xylose (MMGX) as the source of carbon. Online physiological monitoring indicates slower growth of L. starkeyi with PCS as the carbon source than with purified sugars (Fig. 3). To account for this, we collected samples for in-depth analysis at equivalent physiological timepoints post-inoculation. These included sampling during

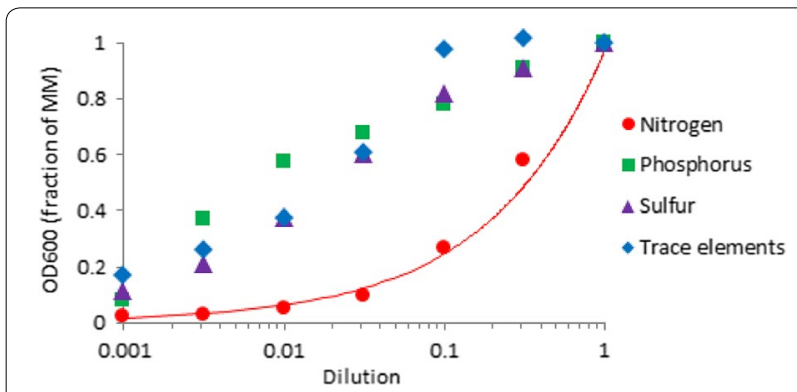

Fig. 2 Growth-limiting nutrients in MMGX medium. L. starkeyi was inoculated to an OD600 of 0.001 in MMGX modified to reduce the concentration of specific nutrients and grown for a week in shake flasks at $30^{\circ} \mathrm{C}$ and $200 \mathrm{rpm}$. Biomass production is most sensitive to the concentration of nitrogen in MMGX medium biomass production and around the time of nitrogen depletion which coincides with the onset of rapid lipid accumulation (Fig. 3).

\section{Metabolic transitions during batch lipid accumulation}

Gene expression in L. starkeyi during batch bioreactor cultivation was quantified by RNA-seq (Additional file 1). Global gene expression profiles for $L$. starkeyi grown in both MMPCS and MMGX were hierarchically clustered. The gene expression profiles clustered into three groups that correspond to physiological phases of the batch culture (Fig. 4). These include growth phase and initial biomass accumulation, a transition phase, and then accumulation of lipids. The early growth phase and late lipid accumulation phase expression profiles cluster tightly, while the transition phase profiles cluster more poorly. This indicates a relatively constant pattern of expression during the growth and lipid accumulation phases with a highly dynamic transition in-between.

In both the MMPCS and MMGX medium, the transition phase is associated with depletion of ammonium and glucose and results in similar patterns of gene expression change (Fig. 5). Gene ontology (GO) term enrichment analysis was performed to identify specific processes, functions, and compartments associated with the upand down-regulated clusters of genes (Table 2). Genes involved in transport and carbohydrate metabolism are up-regulated during the transition suggesting that the cells are beginning to scavenge nutrients and engage in a broader range of metabolic activities. Ribosomal and translation associated genes are particularly down-regulated at the transition to lipid accumulation as would be expected when nitrogen for de novo amino acid biosynthesis is depleted.
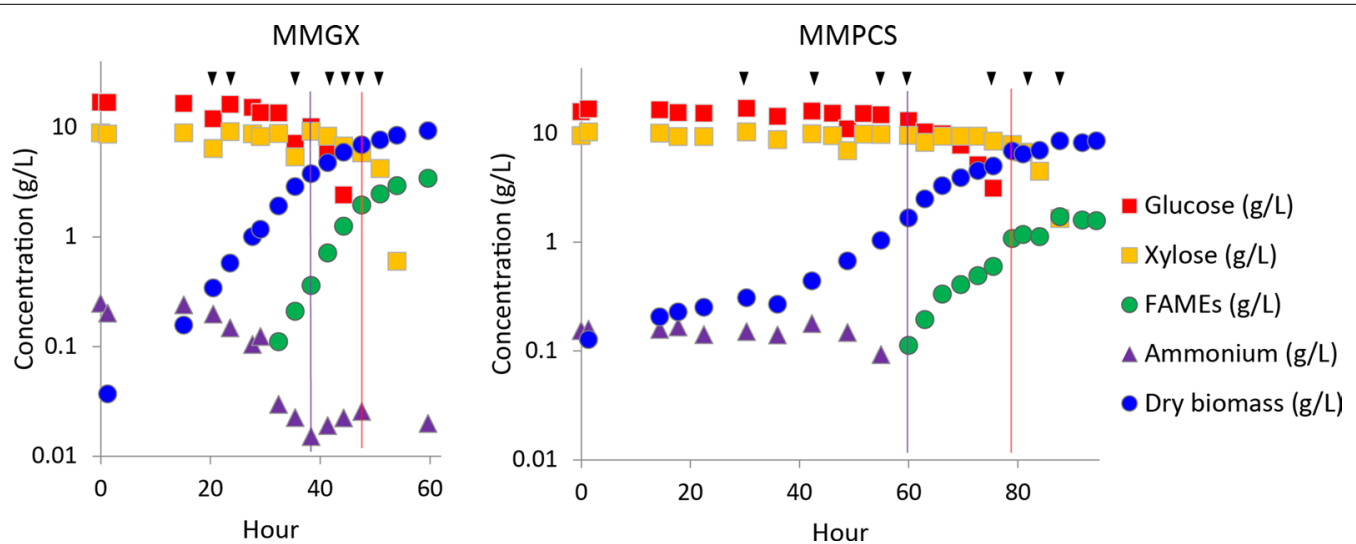

Fig. 3 Physiological analysis of batch cultivation in a 20-L bioreactor. L. starkeyi grown with equivalent amounts of the sugars, glucose and xylose, supplied in either purified form (MMGX) or from PCS (MMPCS) was cultivated in nitrogen-limiting conditions and sampled at physiologically equivalent stages of growth and lipid accumulation. Triangles indicate time-points assessed by transcriptomics. Purple and red lines indicate the point at which glucose and ammonium reach undetectable levels 

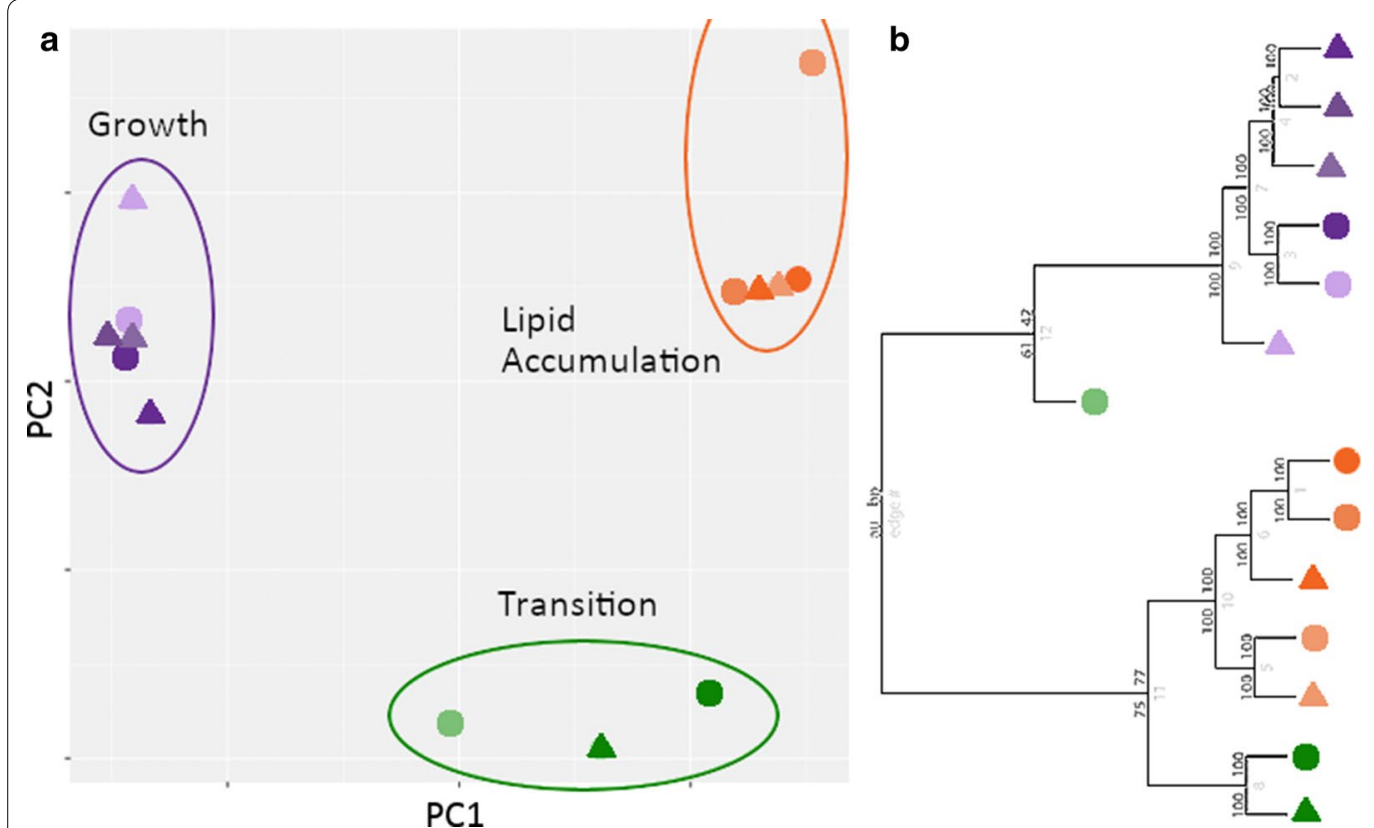

MMGX 21h

MMGX 24h

MMGX 35h

MMGX 44h

MMGX 48h

MMGX 51h

MMGX 54h

MMPCS 26h

$\triangle \mathrm{MMPCS} 42 \mathrm{~h}$

$\triangle \mathrm{MMPCS} 55 \mathrm{~h}$

$\triangle \mathrm{MMPCS} 60 \mathrm{~h}$

$\triangle \mathrm{MMPCS} 76 \mathrm{~h}$

$\triangle$ MMPCS 81h

MMPCS $88 \mathrm{~h}$

Fig. 4 Clustering of global transcriptome profiles during batch cultivation. a Principle Component Analysis using singular value decomposition. $\mathbf{b}$ Hierarchical clustering using the average method of correlation distances. Bootstrap values were calculated from 1000 replicates. The samples can be distinguished into three phases; growth, transition, and lipid accumulation based on similarity of the transcriptome profiles

The initiation of lipid accumulation involves dynamic changes in expression of metabolic genes that are consistent, regardless of growth on PCS or purified glucose and xylose (Fig. 5). Genes necessary for assimilation of ammonium (glt1 and gdh2) are down-regulated as are the genes directing pyruvate toward alpha-ketoglutarate (pyc2, cit2, aco1, idp1, idh1, idh2) through the TCA cycle. Genes for the production of fatty acids from citrate are up-regulated (acl1, acl2, acc1, fas1, fas 2) as are the genes for de novo synthesis of triglycerides via incorporation of fatty acids onto a glycerol-3P backbone (sct1, slc1, pah1, dga1). Interestingly, genes that breakdown triglycerides are also up-regulated (tgl1, $\operatorname{tgl}, \operatorname{tgl} 4, f a a 3)$ as was found for nitrogen limitation in Y. lipolytica [38]. The conserved phenomenon of simultaneous triglyceride production and utilization remains perplexing. However, deletion of tgl4, pex 10, or $m f e 1$ did not increase lipid accumulation in L. starkeyi (Dai et al.; unpublished data) suggesting that breakdown of lipids via beta-oxidation is insignificant during nutrient limitation, consistent with early findings on lipid turnover during carbon limitation [39].

\section{Regulation of the transition to lipid accumulation}

The ammonium depletion induced transition to lipid accumulation is associated with global transcriptome remodeling. To dissect this further, genes were divided into k-means clusters based on their expression pattern across both medium types (Fig. 5). The promoter regions of the genes within each cluster were analyzed for over-represented DNA sequence motifs to discover specific transcriptional regulators associated with the transition. In general, genes that are up-regulated during the transition to lipid accumulation are enriched for $5^{\prime}$-CCCCDC-3' $(p<1 \mathrm{E}-27)$ and/or $5^{\prime}$-GATAAG $-3^{\prime}(p<1 \mathrm{E}-9)$ motifs in their promoters. In both the MMPCS and the MMGX medium nitrogen is depleted and is associated with up-regulation of genes with 5'-GATAAG-3' motifs in their promoters followed by

(See figure on next page.)

Fig. 5 Transcriptome remodeling during the transition to lipid accumulation. a Transcriptome profiles from L. starkeyi growing on either MMPCS or MMGX were k-means clustered and ordered based on average slope of the fold-change. Specific DNA motifs are enriched in the promoters of genes in clusters with the most positive and negative fold-change slopes. Enriched biological process gene ontology terms were identified from groups of genes with the specific DNA motifs in their promoters. The specific DNA motifs are associated with transcriptional regulators in $S$. cerevisiae. $\mathbf{b}$ Expression fold-change values from the transition point mapped to central metabolism pathways and lipid biosynthesis pathways are highly similar for L. starkeyi grown on MMPCS and MMGX 


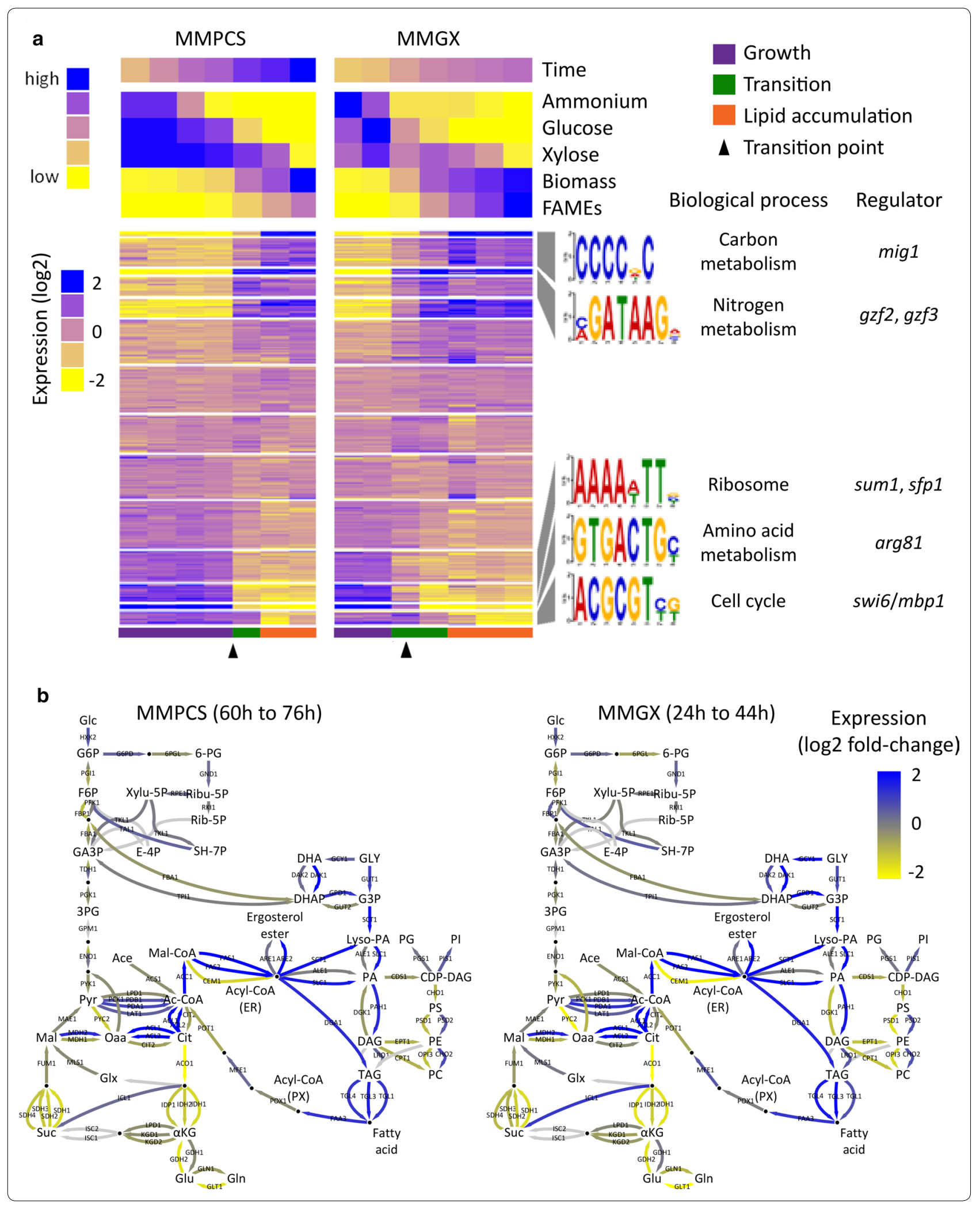


Table 2 Gene ontology term enrichment during transition to lipid accumulation

\begin{tabular}{lll}
\hline GO term & $\begin{array}{l}\text { Fold } \\
\text { enrichment }\end{array}$ & Corrected $p$ value \\
\hline $\begin{array}{lll}\text { Up-regulated gene clusters } \\
\text { Integral to membrane }\end{array}$ & 1.98 & $7.81 \mathrm{E}-27$ \\
Transporter activity & 2.40 & $3.14 \mathrm{E}-23$ \\
Oxidoreductase activity & 1.88 & $1.13 \mathrm{E}-12$ \\
L-arabinose isomerase activity & 2.86 & $7.23 \mathrm{E}-12$ \\
Carbohydrate transport & 2.53 & $8.91 \mathrm{E}-09$ \\
Sugar:hydrogen symporter activity & 2.65 & $1.30 \mathrm{E}-08$ \\
Carbohydrate metabolic process & 2.23 & $2.81 \mathrm{E}-07$ \\
Nucleobase, nucleoside, nucleotide & 3.71 & $1.25 \mathrm{E}-04$ \\
$\quad$ and nucleic acid transport & & \\
Transcription factor activity & 1.75 & $7.26 \mathrm{E}-04$ \\
Hydrolase activity, hydrolyzing & 2.45 & $7.01 \mathrm{E}-03$ \\
$\quad$ O-glycosyl compounds & & \\
Down-regulated gene clusters & & \\
Structural constituent of ribosome & 4.35 & $1.57 \mathrm{E}-57$ \\
Translation & 3.59 & $1.13 \mathrm{E}-56$ \\
RNA binding & 2.97 & $1.41 \mathrm{E}-10$ \\
Protein folding & 2.99 & $1.05 \mathrm{E}-06$ \\
Unfolded protein binding & 3.55 & $2.65 \mathrm{E}-06$ \\
rRNA processing & 4.11 & $3.51 \mathrm{E}-04$ \\
Ribosome biogenesis and assembly & 4.79 & $7.78 \mathrm{E}-04$ \\
ATP binding & 1.41 & $2.64 \mathrm{E}-03$ \\
Translational elongation & 4.32 & $5.72 \mathrm{E}-03$ \\
Aminoacyl-tRNA ligase activity & 2.51 & $3.48 \mathrm{E}-02$ \\
\hline Combined analys of the clusters of & & \\
\hline
\end{tabular}

Combined analysis of the clusters of genes up- and down-regulated during the transition. $p$ value was corrected for multiple comparisons using the Bonferron method

depletion of glucose and up-regulation of genes with $5^{\prime}$-CCCCDC-3' motifs in their promoters (Fig. 5a).

The $5^{\prime}$-CCCCDC-3' motif is associated with genes involved in carbon metabolism and is similar to the sequence bound by Mig1p in S. cerevisiae [40] and CreAp in filamentous fungi such as Aspergillus nidulans [41]. This motif and its bound transcriptional regulators are involved in the utilization of alternative carbon sources and silencing of genes via carbon catabolite repression across fungal species [42-46]. In both medium types, xylose utilization begins just prior to, or concurrent with, depletion of glucose (Figs. 3, 6) when genes involved in the xylose utilization pathway (xylose reductase, xylulose kinase, and xylitol dehydrogenase) are up-regulated (Fig. 6) during the major transcriptional shift that occurs when lipids begin to accumulate. Analysis of the promotor regions revealed $5^{\prime}$-CCCCDC- $3^{\prime}$ motifs in close proximity to the predicted transcription start site in the most dynamic xylose utilization genes ( $x r d, 5651 ; x k s$, 6746; $x d h, 3740 ; x d h, 72797)$, while $x d h$ (66535) does not change much in expression at this transition and does not exhibit the $5^{\prime}$-CCCCDC- $3^{\prime}$ motif in its promoter (Fig. 6). This suggests that carbon catabolite repression regulates utilization of xylose in L. starkeyi. Expression of the creA homolog (74306), while not as dynamic as the xylose utilization genes, increases significantly at the transition point suggesting that it is self-regulated as would be expected with the large number of $5^{\prime}$-CCCCDC-3' sites in close proximity to its transcription start site (Fig. 6). Increased expression of the repressor responsible for carbon catabolite repression at the point when repression is lifted is somewhat counterintuitive but may allow for abundant $c r e A$-derived transcript or protein to respond rapidly to the presence of a preferred carbon source through translational or post-translational mechanisms. In Aspergillus nidulans, import of CreAp into the nucleus is dependent on phosphorylation by Protein Kinase A [47]; while in S. cerevisiae, Mig1p is phospho-regulated by the Snf1p kinase [48] suggesting that transcriptional regulation of creA may play only a minor role.

The $5^{\prime}$-GATAAG- $3^{\prime}$ motif is similar to that bound by the GATA binding family of zinc-finger transcription factors. In S. cerevisiae, this includes four transcription factors (gat1 and gln3; dal80 and gzf3) that activate and repress nitrogen assimilation genes, respectively [42, 49-52]; while the oleaginous yeast $Y$. lipolytica has two GATA binding zinc-finger transcription factors that activate $(g z f 2)$ and repress $(g z f 3)$ nitrogen metabolism genes [44] in response to alternative nitrogen sources, similar to the case in filamentous ascomycetes, such as $A$. nidulans and Neurospora crassa [53-55]. The L. starkeyi genome encodes one gene each that belongs to the nitrogen responsive activator (Lipst1_1 protein ID 424) and repressor (Lipst1_1 protein ID 45435) families [44] as well as homologs of iron responsive GATA binding transcription factors [56] (Lipst1_1 protein ID 73379) and the light-responsive GATA binding transcription factor $w c$ 2 [57] (Lipst1_1 protein ID 71310). None of these transcription factors are differentially expressed during the transition to lipogenesis.

Genes that are down-regulated after the transition phase have $5^{\prime}$-AAAAWTT- $3^{\prime}(p<1 \mathrm{E}-35), 5^{\prime}$-GTGACT G-3' $(p<1 \mathrm{E}-8)$, and $5^{\prime}$-ACGCGT-3' $(p<1 \mathrm{E}-5)$ motifs overrepresented in their promoter regions. Gene ontology term analysis of genes with these DNA sequence motifs in their promoters found that they are associated with the ribosome, amino acid metabolism, and the cell cycle, respectively. All three of these motifs bear a similarity to binding sites of transcriptional regulators in $S$. cerevisiae. These include Sum1p [58, 59], Sfp1p [60-62], the amino acid metabolism regulator Arg81p [63, 64], and the Swi6p/Mbp1p cell cycle regulatory complex [65, 66] (Fig. 5). This suite of motifs enriched in down-regulated genes emphasizes the interplay between depletion 


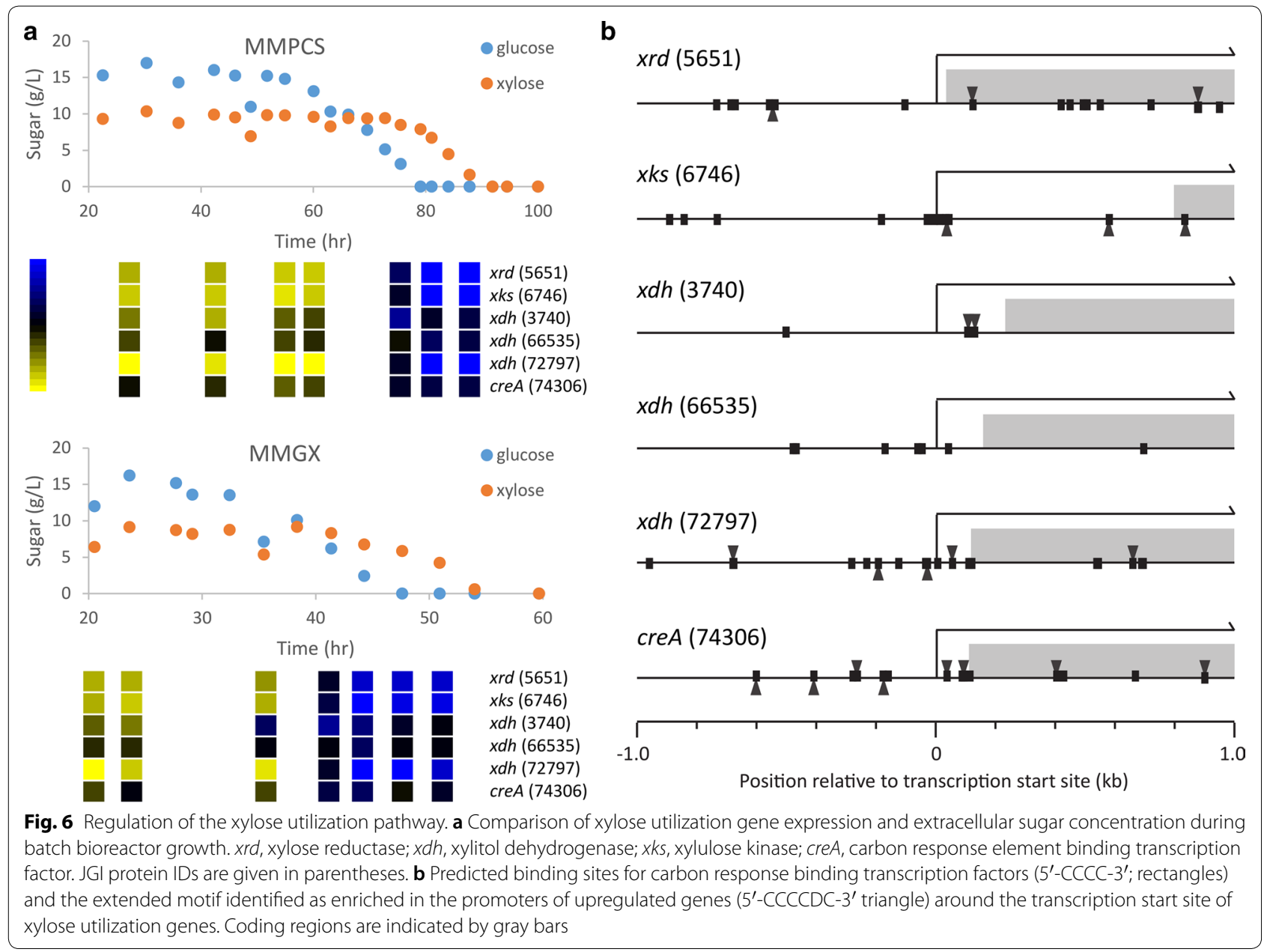

of nitrogen, translation, and cell cycle regulation, and suggests that $L$. starkeyi responds to nitrogen depletion by reducing amino acid anabolism and translation of new proteins, as well as cell division by halting at the G1/S check point. Analysis of the response to nitrogen depletion in the oleaginous yeast $Y$. lipolytica found a similar response $[38,67]$ that is dependent on the G1 cyclin $\operatorname{cln} 3$ in S. cerevisiae [68].

\section{Differential analysis of clean sugars and PCS}

Genes significantly altered in expression between the MMPCS and MMGX medium (adjusted $p$ value $<0.01$ and fold-change $>2$ ) were identified for each of the three phases of batch cultivation (growth, transition, and lipid accumulation) to assess the effect of additional compounds present in the PCS. During growth phase, 73 genes were identified as differentially expressed; while fewer were found during the transition (16) and lipid accumulation (28) phases suggesting that the early stages of growth are when the majority of processes specific to the MMPCS medium occur. Three genes are down-regulated and 55 up-regulated specifically during the growth phase in MMPCS. All three down-regulated genes are transporters; while the up-regulated genes are generally uncharacterized but enriched for proteins involved in regulation of oxidoreductase activity (Lipst1_1 protein ID 68636, 76455, 155344, 243010, 2656, 97553, 76225, 58746, 163820, 5102, 78080, 146211, 2092, $146211,76363,117871$, and 323398) and transport (3675, 7303, 114515, 76372, 52551, and 7145).

Most of the differentially expressed genes in the transition and lipid accumulation phases are found in more than one phase (Fig. 7). These 19 genes that are differentially expressed in more than one of the phases are indicative of a longer-term PCS-specific response. Examination of this set of genes revealed that pyruvate decarboxylase (Lipst1_1 protein ID 70370) is down-regulated in MMPCS (Table 3); while many more genes are upregulated, including a variety of enzymes and transporters. In S. cerevisiae, $p d c 1$ is important for fermentation to ethanol in anaerobic conditions as well as resistance to a variety of chemicals [69]. We have observed ethanol 


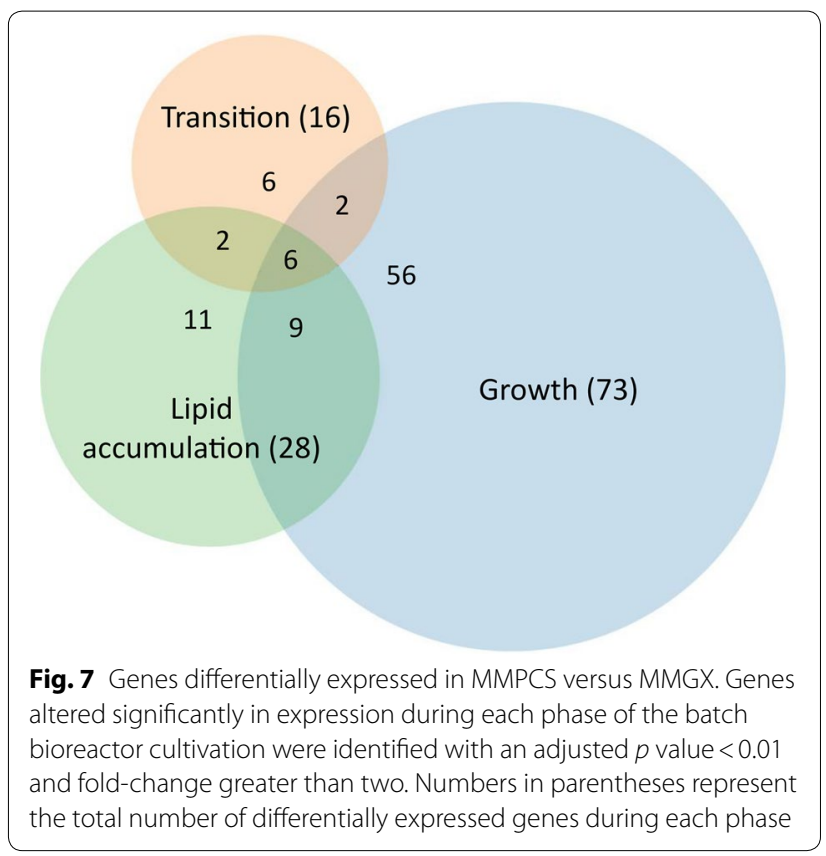

production by $L$. starkeyi in oxygen-limited conditions $(0.18 \pm 0.03 \mathrm{wt} \%$ after 5 days in shake flasks) but not in aerobic conditions. However, further work will need to be done to understand if and why $L$. starkeyi may be undergoing a fermentation response in MMGX.

The persistently up-regulated genes include an aldehyde (Lipst1_1 protein ID 68709) and alcohol dehydrogenase (5082) with homologs known to function in detoxification of cinnamic acids, furfural, and hydroxymethylfurfural [70-72]. Four transporters are up-regulated including two with unknown functions that are homologous to a multi-drug resistance transporter (291194), and a low-affinity ammonium transporter (258339) [73]. The polyamine transporter (6033) similar to tpo1 [74] is upregulated as is a predicted monocarboxylate transporter (5601). However, the homolog of 5601 in S. cerevisiae, $m c h 5$, is involved in riboflavin rather than monocarboxylate transport $[75,76]$ suggesting a role for riboflavin or FAD-dependent processes in general in utilization of MMPCS medium. Intriguingly, genes with a predicted nucleoside diphosphate sugar epimerase (3194) and an oxidoreductase (3195) domain are both up-regulated, particularly during early growth phase and are next to each other on the chromosome though expressed from different promoters. A handful of other genes with poor functional characterization are strongly up-regulated in MMPCS including a predicted nitroreductase, an $\mathrm{NAD}(\mathrm{P}) \mathrm{H}$-dependent $\mathrm{FMN}$ reductase, an $\mathrm{NADH}$

Table 3 Genes differentially expressed in MMPCS versus MMGX

\begin{tabular}{|c|c|c|c|c|}
\hline \multirow{2}{*}{$\begin{array}{l}\text { GeneID } \\
\text { L. starkeyi }\end{array}$} & \multirow[t]{2}{*}{ Description } & \multirow[t]{2}{*}{ Growth } & \multicolumn{2}{|c|}{ Fold-change $(\log 2)$} \\
\hline & & & Transition & $\begin{array}{l}\text { Lipid } \\
\text { accumulation }\end{array}$ \\
\hline 201508 & Conserved hypothetical & 8.51 & 4.64 & 2.76 \\
\hline 5082 & Cinnamyl alcohol dehydrogenase & 5.64 & 4.81 & 4.16 \\
\hline 201186 & Orphan & 6.79 & 3.54 & 3.49 \\
\hline 170668 & Orphan & 5.59 & 3.55 & 3.20 \\
\hline 6033 & Polyamine transporter & 4.48 & 3.89 & 2.95 \\
\hline 68709 & Aldehyde dehydrogenase (toxD) & 4.87 & 3.69 & 2.39 \\
\hline 3194 & Nucleoside diphosphate sugar epimerase & 5.52 & 2.48 & 2.07 \\
\hline 73608 & Nitroreductase & 2.12 & 4.17 & 3.19 \\
\hline 291194 & $\mathrm{ABC}$ transporter & 3.56 & 2.97 & 2.69 \\
\hline 73626 & Conserved hypothetical & 4.94 & 1.83 & 1.99 \\
\hline 3195 & Oxidoreductase & 4.50 & 1.79 & 2.20 \\
\hline 74501 & Conserved hypothetical & 2.41 & 3.32 & 2.68 \\
\hline 258339 & MFS transporter & 2.62 & 3.23 & 2.49 \\
\hline 76819 & NAD(P)H-dependent FMN reductase & 4.15 & 2.94 & 0.73 \\
\hline 5601 & Monocarboxylate transporter & 2.90 & 1.90 & 1.65 \\
\hline 119382 & Conserved hypothetical & 3.60 & 0.80 & 1.69 \\
\hline 68269 & NADH dehydrogenase & 0.21 & 2.77 & 1.83 \\
\hline 108039 & Orphan & -2.56 & -1.79 & -1.43 \\
\hline 70370 & Pyruvate decarboxylase & -0.73 & -2.30 & -1.10 \\
\hline
\end{tabular}

Genes differentially expressed during more than one phase of growth, transition, or lipid accumulation. Significantly up-regulated genes are italics, while downregulated genes are bold italics 
dehydrogenase, and four conserved genes of unknown function (Table 3).

Three genes are down-regulated and three up-regulated specifically during the transition phase in MMPCS. Two metal transporters (Lipst1_1 protein ID 71180 and 89156) with homology to the high-affinity zinc transporter $z r t 1$ [77] are more highly expressed in the MMGX medium suggesting that PCS has a higher concentration of zinc, which regulates expression of this transporter in S. cerevisiae [78]. Genes specifically up-regulated during the transition phase include a predicted galactokinase (75890) and L-arabinose isomerase (89272). These genes are involved in utilization of the sugars galactose and arabinose that are likely to be present in small quantities in MMPCS but not MMGX.

Four genes are down-regulated and seven up-regulated specifically during the lipid accumulation phase in MMPCS. A predicted pantothenate MFS transporter (Lipst1_1 protein ID 716) is down-regulated, again suggesting that MMPCS contains a higher concentration of a trace nutrient, in this case pantothenate. A predicted cyclopropane-fatty-acyl-phospholipid synthase (4209) is down-regulated. In Escherichia coli, this lipid modification is important for acid and freeze-thaw tolerance suggesting that plasma membrane remodeling may be important for growth on PCS $[79,80]$. Genes specifically up-regulated during the lipid accumulation phase include an uncharacterized cytochrome p450 (115210) and a phenylacrylic acid decarboxylase (76260), the homolog (pad1) of which confers resistance to cinnamic acids in S. cerevisiae [81]. A predicted dienelactone hydrolase orthologous to aim2, which is involved in mitochondrial function but does not have a defined role [82], is also upregulated. In bacteria, genes with this domain play a role in detoxification of chloroaromatics $[83,84]$ suggesting another class of molecules that could play a role in inhibition of growth on PCS.

\section{Discussion}

Robust growth of microorganisms and carbon-efficient production of biofuels using lignocellulosic biomass as a substrate are a challenge to the development of an economically viable and sustainable bio-economy. Efficient bioconversion processes require physical pretreatment and enzymatic hydrolysis of lignocellulosic biomass to release simple sugars for rapid conversion. These sugar-rich hydrolysates generally contain plant-derived breakdown products that inhibit the growth of microorganisms and overall bioconversion efficiency. We found that acetic acid and furfural present at levels found in PCS inhibit the growth of the robust lipid producer $L$. starkeyi when challenged to grow from a low initial cell density in minimal medium (Fig. 1). Growth inhibition by these compounds in PCS during batch bioreactor cultivation is overcome, however, possibly due to inoculation at a higher initial cell density (Fig. 3).

Growth on PCS presents a challenge to most microorganisms due to various toxic compounds. L. starkeyi is able to overcome this challenge, grow robustly, and accumulate lipids in a timely manner on PCS (Fig. 3). To further our understanding of the impact of inhibitory compounds in PCS, we compared L. starkeyi grown on PCS versus a clean glucose and xylose mixture. We analyzed expression of RNA during batch cultivation to identify genes associated with growth in the presence of inhibitors in PCS, so that a more robust strain can be engineered. Resistance could manifest itself as the ability to truly catabolize inhibitors such as acetate and phenolics from lignin breakdown, or inactivate the inhibitory functional groups by reduction of harmful aldehyde and ketone groups (furfural, HMF, acetaldehyde) to alcohols) that can cause cross-linking and inactivation of biological macromolecules, especially proteins, or continuous export of inhibitors that cross the plasma membrane.

We found that while the amount of time required for growth and production of lipids was extended on PCS (Fig. 3), the overall trends in gene expression and their relation to nutrient depletion were highly similar to that of growth on clean sugars (Figs. 4, 5). We, thus, identified and compared equivalent physiological conditions during growth on PCS and clean sugars rather than equivalent points in time during the batch lipid accumulation runs. Clustering identified two robust states, one associated with early growth and another associated with lipid accumulation following depletion of ammonium and glucose. Understanding the transition to lipid accumulation is particularly interesting in oleaginous biofuel production hosts such as $L$. starkeyi. Early work on lipid accumulation identified limitation of macronutrients including nitrogen, phosphorus, and sulfur in the presence of excess carbon as a readily controllable method to induce lipid accumulation [23, 8588]. Here, we identified promoter motifs and enriched GO terms associated with gene sets that tend to be up- and down-regulated between the growth and lipid accumulation phases. Up-regulated genes tend to be enriched for motifs in their promoters associated with carbon and nitrogen catabolite repression (Fig. 5). In $S$. cerevisiae, these processes are controlled by sequence specific transcription factors [42]. At the onset of lipid accumulation, genes silenced by carbon and nitrogen catabolite repression are activated suggesting derepression of these processes in an attempt by the cells to scavenge additional sources of carbon and nitrogen. Induction of the repressed genes occurs prior to depletion of glucose and is associated more with depletion 
of nitrogen suggesting nitrogen starvation as the initial motivator for the change in gene expression. Interestingly, genes typically silenced by carbon catabolite repression in ascomycetes, such as the genes for xylose utilization [89-92], are activated prior to depletion of glucose. Xylose utilization also begins prior to depletion of glucose. We examined these genes specifically and found that they are enriched for motifs near their transcription start site associated with carbon but not nitrogen catabolite repression (Fig. 6), further confirming that carbon catabolite repression is controlling their expression and is lifted prior to complete glucose depletion. The interplay between carbon and nitrogen catabolite repression has not been fully elucidated, particularly during dynamic processes. In the oleaginous yeast $Y$. lipolytica, genes with the carbon catabolite repression motif in their promoter regions are silenced when nitrogen catabolite repression is lifted [38] and this effect is reproduced by deletion of $g z f 3$, which is required for silencing of genes via nitrogen catabolite repression [44]. This is opposed to the findings here, suggesting that the presence of xylose in these experiments is signaling the cells to activate genes silenced by carbon catabolite repression prior to complete utilization of glucose.

Analysis of differentially expressed genes found that most are identified specifically during growth phase. This observation supports the notion that PCS has a greater impact on the growth phase of the organism, which requires a large array of complex biosynthetic reactions, than on the lipid accumulation phase under nitrogen starvation, where cell growth has basically ceased (Fig. 7). The majority of the differentially expressed genes are up-regulated demonstrating that growth on MMPCS requires additional metabolic activities. During growth phase, we identified a variety of uncharacterized enzymes and conserved proteins of unknown function that may play a role in utilization and/or detoxification of chemical components of PCS. Three of the up-regulated enzymes are similar to those known to play a role in detoxification in other organisms (Lipst1_1 protein ID 68709, 5082, and 76260). These include two medium-chain dehydrogenase/ reductase family members belonging to the cinnamyl alcohol dehydrogenase family (5082) and the quinone oxidoreductase family (68709), respectively. In S. cerevisiae, the cinnamyl alcohol dehydrogenases (adh6 and $a d h 7$ ) exhibit broad substrate specificity, and are involved in lignin degradation and in detoxification of hydroxymethylfurfural $[72,93,94]$. The quinone oxidoreductase family protein is homologous to the broad substrate aldehyde dehydrogenase (YNL134c) in S. cerevisiae, which is up-regulated in the presence of furfural and detoxifies it to 2-furanmethanol [70]. It is likely that $L$. starkeyi detoxifies PCS using these enzymes.

\section{Conclusions}

In summary, we compared the physiology and gene expression of $L$. starkeyi during batch cultivation on "clean" sugars and the more complex carbon source PCS. Overall growth and metabolism are similar on the two carbon sources with the primary difference occurring during early growth phase when genes specific to growth on PCS are up-regulated. Some of the genes identified are implicated in detoxification of compounds present in PCS in other fungi but most are uncharacterized and need to be tested specifically for function. This work provides a foundation for understanding the metabolic capabilities necessary for growth on a complex and potentially toxic substrate being considered for industrial use as a lignocellulosic biofuel feedstock.

\section{Additional file}

Additional file 1. Excel file that contains metabolite quantification during the bioreactor runs as well as raw RPKM values from RNA-seq. Genes that are differentially expressed between the MMPCS and MMGX bioreactor runs during at least one phase are listed along with their fold-change values.

\section{Abbreviations}

GC: gas chromatography; GO: gene ontology; GC: gas chromatography; GX: glucose and xylose; HMF: hydroxymethylfurfural; HPLC: high-pressure liquid chromatography; MM: minimal medium; PCS: pretreated corn stover; FAMEs: fatty acid methyl esters.

\section{Acknowledgements}

The authors are thankful for funding provided by the Bioenergy Technologies Office, U.S. Department of Energy.

\section{Authors' contributions}

KRP, JRC, JK, EAP, DEC, ZD, SD, BAH, MGB, and JKM conceived and designed the experiments. KRP, JRC, JK, EAP, DEC, ZD, SD, BAH, and MGB performed the experiments and analyzed the data. KRP, JRC, and JK wrote the paper. All authors read and approved the final manuscript.

\section{Funding}

Funding was provided by the Bioenergy Technologies Office, U.S. Department of Energy through award number 2.3.2.103. Pacific Northwest National Laboratory is multi-program national laboratory operated by Battelle for the DOE under Contract No. DE-AC05-76RLO1830.

\section{Availability of data and materials}

All data generated or analyzed during this study are included in this published article and its supplementary information files, or in a public archive. Raw transcriptome data have been deposited at NCBI SRA under Bioproject PRJNA542162 (accession numbers SRR9036793, SRR9036792, SRR9036791, SRR9036790, SRR9036789, SRR9036788, SRR9036787, SRR9036786, SRR9036785, SRR9036784, SRR9036783, SRR9036782, SRR9036781, SRR9036780).

Ethics approval and consent to participate Not applicable. 


\section{Consent for publication}

Not applicable.

\section{Competing interests}

The authors declare that they have no competing interests.

\section{Author details}

${ }^{1}$ Pacific Northwest National Laboratory, Richland, WA, USA. ${ }^{2}$ Joint BioEnergy Institute, Emeryville, CA, USA.

Received: 13 April 2019 Accepted: 19 June 2019

Published online: 26 June 2019

\section{References}

1. Adrio JL. Oleaginous yeasts: promising platforms for the production of oleochemicals and biofuels. Biotechnol Bioeng. 2017;114(9):1915-20.

2. Qin L, Liu L, Zeng AP, Wei D. From low-cost substrates to single cell oils synthesized by oleaginous yeasts. Bioresour Technol. 2017;245:1507-19.

3. Sitepu IR, Garay LA, Sestric R, Levin D, Block DE, German JB, Boundy-Mills $\mathrm{KL}$. Oleaginous yeasts for biodiesel: current and future trends in biology and production. Biotechnol Adv. 2014;32(7):1336-60.

4. Kumar AK, Sharma S. Recent updates on different methods of pretreatment of lignocellulosic feedstocks: a review. Bioresour Bioprocess. 2017;4(1):7.

5. Ko JK, Um Y, Park YC, Seo JH, Kim KH. Compounds inhibiting the bioconversion of hydrothermally pretreated lignocellulose. Appl Microbiol Biotechnol. 2015;99(10):4201-12.

6. Baral NR, Shah A. Microbial inhibitors: formation and effects on acetonebutanol-ethanol fermentation of lignocellulosic biomass. Appl Microbiol Biotechnol. 2014;98(22):9151-72.

7. Saha BC, Bothast RJ. Pretreatment and enzymatic saccharification of corn fiber. Appl Biochem Biotechnol. 1999;76(2):65-77.

8. Szczodrak J. The enzymatic hydrolysis and fermentation of pretreated wheat straw to ethanol. Biotechnol Bioeng. 1988;32(6):771-6.

9. Zhang $\mathrm{H}$, Zhang J, Bao J. High titer gluconic acid fermentation by Aspergillus niger from dry dilute acid pretreated corn stover without detoxification. Bioresour Technol. 2016;203:211-9.

10. Zhu JQ, Li X, Qin L, Li WC, Li HZ, Li BZ, Yuan YJ. In situ detoxification of dry dilute acid pretreated corn stover by co-culture of xylose-utilizing and inhibitor-tolerant Saccharomyces cerevisiae increases ethanol production. Bioresour Technol. 2016;218:380-7.

11. Jiang T, Qiao H, Zheng Z, Chu Q, Li X, Yong Q, Ouyang J. Lactic acid production from pretreated hydrolysates of corn stover by a newly developed Bacillus coagulans strain. PLoS ONE. 2016;11(2):e0149101.

12. Jonsson $\sqcup$, Martin C. Pretreatment of lignocellulose: formation of inhibitory by-products and strategies for minimizing their effects. Bioresour Technol. 2016;199:103-12.

13. Piotrowski JS, Zhang Y, Bates DM, Keating DH, Sato TK, Ong IM, Landick R. Death by a thousand cuts: the challenges and diverse landscape of lignocellulosic hydrolysate inhibitors. Front Microbiol. 2014;5:90.

14. Zha Y, Westerhuis JA, Muilwijk B, Overkamp KM, Nijmeijer BM, Coulier L, Smilde AK, Punt PJ. Identifying inhibitory compounds in lignocellulosic biomass hydrolysates using an exometabolomics approach. BMC Biotechnol. 2014;14:22

15. Qureshi AS, Zhang J, Bao J. High ethanol fermentation performance of the dry dilute acid pretreated corn stover by an evolutionarily adapted Saccharomyces cerevisiae strain. Bioresour Technol. 2015;189:399-404.

16. Thompson OA, Hawkins GM, Gorsich SW, Doran-Peterson J. Phenotypic characterization and comparative transcriptomics of evolved Saccharomyces cerevisiae strains with improved tolerance to lignocellulosic derived inhibitors. Biotechnol Biofuels. 2016;9:200.

17. Wang X, Gao Q, Bao J. Enhancement of furan aldehydes conversion in Zymomonas mobilis by elevating dehydrogenase activity and cofactor regeneration. Biotechnol Biofuels. 2017;10:24.

18. Kannisto MS, Mangayil RK, Shrivastava-Bhattacharya A, Pletschke BI, Karp MT, Santala VP. Metabolic engineering of Acinetobacter baylyi ADP1 for removal of Clostridium butyricum growth inhibitors produced from lignocellulosic hydrolysates. Biotechnol Biofuels. 2015;8:198.
19. Chung D, Verbeke TJ, Cross KL, Westpheling J, Elkins JG. Expression of a heat-stable NADPH-dependent alcohol dehydrogenase in Caldicellulosiruptor bescii results in furan aldehyde detoxification. Biotechnol Biofuels. 2015:8:102.

20. Kurosawa K, Laser J, Sinskey AJ. Tolerance and adaptive evolution of triacylglycerol-producing Rhodococcus opacus to lignocellulose-derived inhibitors. Biotechnol Biofuels. 2015;8:76.

21. Radecka D, Mukherjee $V$, Mateo RQ, Stojiljkovic M, Foulquie-Moreno MR, Thevelein JM. Looking beyond Saccharomyces: the potential of nonconventional yeast species for desirable traits in bioethanol fermentation. FEMS Yeast Res. 2015. https://doi.org/10.1093/femsyr/fov053.

22. Pereira FB, Romani A, Ruiz HA, Teixeira JA, Domingues L. Industrial robust yeast isolates with great potential for fermentation of lignocellulosic biomass. Bioresour Technol. 2014;161:192-9.

23. Ratledge C. Yeasts for lipid production. Biochem Soc Trans. 1988;16(6):1088-91.

24. Riley R, Haridas S, Wolfe KH, Lopes MR, Hittinger CT, Goker M, Salamov AA, Wisecaver JH, Long TM, Calvey $\mathrm{CH}$, et al. Comparative genomics of biotechnologically important yeasts. Proc Natl Acad Sci USA. 2016:113(35):9882-7.

25. Gong Z, Wang Q, Shen H, Hu C, Jin G, Zhao ZK. Co-fermentation of cellobiose and xylose by Lipomyces starkeyi for lipid production. Bioresour Technol. 2012;117:20-4.

26. Huang $C$, Chen $X F$, Yang $X Y$, Xiong $L$, Lin $X Q$, Yang J, Wang $B$, Chen $X D$. Bioconversion of corncob acid hydrolysate into microbial oil by the oleaginous yeast Lipomyces starkeyi. Appl Biochem Biotechnol. 2014;172(4):2197-204.

27. Calvey CH, Su YK, Willis LB, McGee M, Jeffries TW. Nitrogen limitation, oxygen limitation, and lipid accumulation in Lipomyces starkeyi. Bioresour Technol. 2016;200:780-8.

28. Oguro Y, Yamazaki H, Shida Y, Ogasawara W, Takagi M, Takaku H. Multicopy integration and expression of heterologous genes in the oleaginous yeast, Lipomyces starkeyi. Biosci Biotechnol Biochem. 2015;79(3):512-5.

29. Oguro Y, Yamazaki H, Ara S, Shida Y, Ogasawara W, Takagi M, Takaku H. Efficient gene targeting in non-homologous end-joining-deficient Lipomyces starkeyi strains. Curr Genet. 2017;63(4):751-63.

30. Dai Z, Deng S, Culley DE, Bruno KS, Magnuson JK. Agrobacterium tumefaciens-mediated transformation of oleaginous yeast Lipomyces species. Appl Microbiol Biotechnol. 2017;101(15):6099-110.

31. Dai Z, Magnuson J, Deng S, Bruno K, Culley D. Agrobacterium-mediated transformation of lipomyces. In. Edited by Patent US, Current International Class: C12P 21/06 (20060101); C12N 1/19 (20060101); C12N 15/81 (20060101); C12P 7/64 (20060101); C12Q 1/04 (20060101) edn. Richland: Battelle Memorial Institute. 2018.

32. Liao Y, Smyth GK, Shi W. featureCounts: an efficient general purpose program for assigning sequence reads to genomic features. Bioinformatics. 2014;30(7):923-30.

33. Love MI, Huber W, Anders S. Moderated estimation of fold change and dispersion for RNA-seq data with DESeq2. Genome Biol. 2014;15(12):550.

34. Pathan M, Keerthikumar S, Ang CS, Gangoda L, Quek CY, Williamson NA, Mouradov D, Sieber OM, Simpson RJ, Salim A, et al. FunRich: an open access standalone functional enrichment and interaction network analysis tool. Proteomics. 2015;15(15):2597-601.

35. Cline MS, Smoot M, Cerami E, Kuchinsky A, Landys N, Workman C, Christmas R, Avila-Campilo I, Creech M, Gross B, et al. Integration of biological networks and gene expression data using cytoscape. Nat Protoc. 2007;2(10):2366-82.

36. Bailey TL. DREME: motif discovery in transcription factor ChIP-seq data. Bioinformatics. 2011;27(12):1653-9.

37. Gupta S, Stamatoyannopoulos JA, Bailey TL, Noble WS. Quantifying similarity between motifs. Genome Biol. 2007;8(2):R24.

38. Pomraning KR, Kim YM, Nicora CD, Chu RK, Bredeweg EL, Purvine SO, Hu D, Metz TO, Baker SE. Multi-omics analysis reveals regulators of the response to nitrogen limitation in Yarrowia lipolytica. BMC Genom. 2016;17:138.

39. Holdsworth JE, Ratledge C. Lipid turnover in oleaginous yeasts. J Gen Microbiol. 1988;134:339-46.

40. Lundin M, Nehlin JO, Ronne $\mathrm{H}$. Importance of a flanking AT-rich region in target site recognition by the GC box-binding zinc finger protein MIG1. Mol Cell Biol. 1994;14(3):1979-85. 
41. Panozzo C, Cornillot E, Felenbok B. The CreA repressor is the sole DNAbinding protein responsible for carbon catabolite repression of the alcA gene in Aspergillus nidulans via its binding to a couple of specific sites. J Biol Chem. 1998;273(11):6367-72.

42. Conrad M, Schothorst J, Kankipati HN, Van Zeebroeck G, Rubio-Texeira M, Thevelein JM. Nutrient sensing and signaling in the yeast Saccharomyces cerevisiae. FEMS Microbiol Rev. 2014;38(2):254-99.

43. Portnoy T, Margeot A, Linke R, Atanasova L, Fekete E, Sandor E, Hartl L, Karaffa L, Druzhinina IS, Seiboth B, et al. The CRE1 carbon catabolite repressor of the fungus Trichoderma reesei: a master regulator of carbon assimilation. BMC Genom. 2011;12:269.

44. Pomraning KR, Bredeweg EL, Baker SE. Regulation of nitrogen metabolism by GATA zinc finger transcription factors in Yarrowia lipolytica. mSphere. 2017;2(1):e00038-17.

45. David H, Krogh AM, Roca C, Akesson M, Nielsen J. CreA influences the metabolic fluxes of Aspergillus nidulans during growth on glucose and xylose. Microbiology. 2005;151(Pt 7):2209-21.

46. Sun J, Glass NL. Identification of the CRE-1 cellulolytic regulon in Neurospora crassa. PLoS ONE. 2011;6(9):e25654.

47. Ribeiro LFC, Chelius C, Boppidi KR, Naik NS, Hossain S, Ramsey JJJ, Kumar J, Ribeiro LF, Ostermeier M, Tran B, et al. Comprehensive analysis of Aspergillus nidulans PKA phosphorylome identifies a novel mode of CreA regulation. mBio. 2019;10(2):e02825-18.

48. Shashkova S, Wollman AJM, Leake MC, Hohmann S. The yeast Mig1 transcriptional repressor is dephosphorylated by glucose-dependent and -independent mechanisms. FEMS Microbiol Lett. 2017. https://doi. org/10.1093/femsle/fnx133.

49. Cooper TG. Transmitting the signal of excess nitrogen in Saccharomyces cerevisiae from the Tor proteins to the GATA factors: connecting the dots. FEMS Microbiol Rev. 2002;26(3):223-38.

50. ter Schure EG, van Riel NA, Verrips CT. The role of ammonia metabolism in nitrogen catabolite repression in Saccharomyces cerevisiae. FEMS Microbiol Rev. 2000;24(1):67-83.

51. Hofman-Bang J. Nitrogen catabolite repression in Saccharomyces cerevisiae. Mol Biotechnol. 1999:12(1):35-73.

52. Magasanik B, Kaiser CA. Nitrogen regulation in Saccharomyces cerevisiae. Gene. 2002;290(1-2):1-18.

53. Marzluf GA. Genetic regulation of nitrogen metabolism in the fungi. Microbiol Mol Biol Rev. 1997;61(1):17-32.

54. Wiame JM, Grenson M, Arst HN Jr. Nitrogen catabolite repression in yeasts and filamentous fungi. Adv Microb Physiol. 1985;26:1-88.

55. Scazzocchio C. The fungal GATA factors. Curr Opin Microbiol. 2000;3(2):126-31.

56. Haas H, Zadra I, Stoffler G, Angermayr K. The Aspergillus nidulans GATA factor SREA is involved in regulation of siderophore biosynthesis and control of iron uptake. J Biol Chem. 1999;274(8):4613-9.

57. Smith KM, Sancar G, Dekhang R, Sullivan CM, Li S, Tag AG, Sancar C, Bredeweg EL, Priest HD, McCormick RF, et al. Transcription factors in light and circadian clock signaling networks revealed by genomewide mapping of direct targets for neurospora white collar complex. Eukaryot Cell. 2010;9(10):1549-56.

58. Badis G, Chan ET, van Bakel H, Pena-Castillo L, Tillo D, Tsui K, Carlson CD, Gossett AJ, Hasinoff MJ, Warren CL, et al. A library of yeast transcription factor motifs reveals a widespread function for Rsc3 in targeting nucleosome exclusion at promoters. Mol Cell. 2008;32(6):878-87.

59. Irlbacher H, Franke J, Manke T, Vingron M, Ehrenhofer-Murray AE. Control of replication initiation and heterochromatin formation in Saccharomyces cerevisiae by a regulator of meiotic gene expression. Genes Dev. 2005;19(15):1811-22.

60. Zhu C, Byers KJ, McCord RP, Shi Z, Berger MF, Newburger DE, Saulrieta K, Smith Z, Shah MV, Radhakrishnan M, et al. High-resolution DNAbinding specificity analysis of yeast transcription factors. Genome Res. 2009;19(4):556-66.

61. Marion RM, Regev A, Segal E, Barash Y, Koller D, Friedman N, O'Shea EK. Sfp1 is a stress- and nutrient-sensitive regulator of ribosomal protein gene expression. Proc Natl Acad Sci USA. 2004;101(40):14315-22.

62. Newburger DE, Bulyk ML. UniPROBE: an online database of protein binding microarray data on protein-DNA interactions. Nucleic Acids Res. 2009;37(Database issue):D77-82
63. Maclsaac KD, Wang T, Gordon DB, Gifford DK, Stormo GD, Fraenkel E. An improved map of conserved regulatory sites for Saccharomyces cerevisiae. BMC Bioinform. 2006;7:113.

64. De Rijcke M, Seneca S, Punyammalee B, Glansdorff N, Crabeel M. Characterization of the DNA target site for the yeast ARGR regulatory complex, a sequence able to mediate repression or induction by arginine. Mol Cell Biol. 1992;12(1):68-81.

65. Horak CE, Luscombe NM, Qian J, Bertone P, Piccirrillo S, Gerstein M, Snyder M. Complex transcriptional circuitry at the G1/S transition in Saccharomyces cerevisiae. Genes Dev. 2002;16(23):3017-33.

66. Pachkov M, Erb I, Molina N, van Nimwegen E. SwissRegulon: a database of genome-wide annotations of regulatory sites. Nucleic Acids Res. 2007;35(Database issue):D127-31.

67. Kerkhoven EJ, Pomraning KR, Baker SE, Nielsen J. Regulation of aminoacid metabolism controls flux to lipid accumulation in Yarrowia lipolytica. NPJ Syst Biol Appl. 2016;2:16005.

68. Gallego C, Gari E, Colomina N, Herrero E, Aldea M. The Cln3 cyclin is down-regulated by translational repression and degradation during the $\mathrm{G} 1$ arrest caused by nitrogen deprivation in budding yeast. EMBO J. 1997;16(23):7196-206.

69. Pronk JT, Yde Steensma H, Van Dijken JP. Pyruvate metabolism in Saccharomyces cerevisiae. Yeast. 1996;12(16):1607-33.

70. Zhao X, Tang J, Wang X, Yang R, Zhang X, Gu Y, Li X, Ma M. YNL134C from Saccharomyces cerevisiae encodes a novel protein with aldehyde reductase activity for detoxification of furfural derived from lignocellulosic biomass. Yeast. 2015;32(5):409-22.

71. Teutschbein J, Albrecht D, Potsch M, Guthke R, Aimanianda V, Clavaud C, Latge JP, Brakhage AA, Kniemeyer O. Proteome profiling and functional classification of intracellular proteins from conidia of the human-pathogenic mold Aspergillus fumigatus. J Proteome Res. 2010;9(7):3427-42.

72. Larroy C, Pares X, Biosca JA. Characterization of a Saccharomyces cerevisiae NADP(H)-dependent alcohol dehydrogenase (ADHVII), a member of the cinnamyl alcohol dehydrogenase family. Eur J Biochem. 2002;269(22):5738-45.

73. Chiasson DM, Loughlin PC, Mazurkiewicz D, Mohammadidehcheshmeh M, Fedorova EE, Okamoto M, McLean E, Glass AD, Smith SE, Bisseling T, et al. Soybean SAT1 (Symbiotic Ammonium Transporter 1) encodes a bHLH transcription factor involved in nodule growth and $\mathrm{NH} 4+$ transport. Proc Natl Acad Sci USA. 2014;111(13):4814-9.

74. Tomitori H, Kashiwagi K, Sakata K, Kakinuma Y, Igarashi K. Identification of a gene for a polyamine transport protein in yeast. J Biol Chem. 1999;274(6):3265-7

75. Makuc J, Paiva S, Schauen M, Kramer R, Andre B, Casal M, Leao C, Boles E. The putative monocarboxylate permeases of the yeast Saccharomyces cerevisiae do not transport monocarboxylic acids across the plasma membrane. Yeast. 2001;18(12):1131-43.

76. Reihl P, Stolz J. The monocarboxylate transporter homolog Mch5p catalyzes riboflavin (vitamin B2) uptake in Saccharomyces cerevisiae. J Biol Chem. 2005;280(48):39809-17.

77. Zhao H, Eide D. The yeast ZRT1 gene encodes the zinc transporter protein of a high-affinity uptake system induced by zinc limitation. Proc Natl Acad Sci USA. 1996;93(6):2454-8.

78. Gitan RS, Luo H, Rodgers J, Broderius M, Eide D. Zinc-induced inactivation of the yeast ZRT1 zinc transporter occurs through endocytosis and vacuolar degradation. J Biol Chem. 1998;273(44):28617-24.

79. Chang YY, Cronan JE Jr. Membrane cyclopropane fatty acid content is a major factor in acid resistance of Escherichia coli. Mol Microbiol. 1999;33(2):249-59.

80. Grogan DW, Cronan JE Jr. Characterization of Escherichia coli mutants completely defective in synthesis of cyclopropane fatty acids. J Bacteriol. 1986;166(3):872-7.

81. Clausen M, Lamb CJ, Megnet R, Doerner PW. PAD1 encodes phenylacrylic acid decarboxylase which confers resistance to cinnamic acid in Saccharomyces cerevisiae. Gene. 1994;142(1):107-12.

82. Hess DC, Myers CL, Huttenhower C, Hibbs MA, Hayes AP, Paw J, Clore JJ, Mendoza RM, Luis BS, Nislow C, et al. Computationally driven, quantitative experiments discover genes required for mitochondrial biogenesis. PLoS Genet. 2009;5(3):e1000407.

83. Bruckmann M, Blasco R, Timmis KN, Pieper DH. Detoxification of protoanemonin by dienelactone hydrolase. J Bacteriol. 1998;180(2):400-2. 
84. Park YJ, Yoon SJ, Lee HB. A novel dienelactone hydrolase from the thermoacidophilic archaeon Sulfolobus solfataricus P1: purification, characterization, and expression. Biochim Biophys Acta. 2010;1800(11):1164-72

85. Kolouchova I, Matatkova O, Sigler K, Masak J, Rezanka T. Lipid accumulation by oleaginous and non-oleaginous yeast strains in nitrogen and phosphate limitation. Folia Microbiol. 2016;61(5):431-8.

86. Wu S, Hu C, Jin G, Zhao X, Zhao ZK. Phosphate-limitation mediated lipid production by Rhodosporidium toruloides. Bioresour Technol. 2010;101(15):6124-9.

87. Gill CO, Hall MJ, Ratledge C. Lipid accumulation in an oleaginous yeast (Candida 107) growing on glucose in single-stage continuous culture. Appl Environ Microbiol. 1977;33(2):231-9.

88. Wu S, Zhao X, Shen H, Wang Q, Zhao ZK. Microbial lipid production by Rhodosporidium toruloides under sulfate-limited conditions. Bioresour Technol. 2011;102(2):1803-7.

89. Sun J, Tian C, Diamond S, Glass NL. Deciphering transcriptional regulatory mechanisms associated with hemicellulose degradation in Neurospora crassa. Eukaryot Cell. 2012;11(4):482-93.

90. Mach RL, Strauss J, Zeilinger S, Schindler M, Kubicek CP. Carbon catabolite repression of xylanase I (xyn 1) gene expression in Trichoderma reesei. Mol Microbiol. 1996;21(6):1273-81.
91. Prathumpai W, McIntyre M, Nielsen J. The effect of CreA in glucose and xylose catabolism in Aspergillus nidulans. Appl Microbiol Biotechnol. 2004;63(6):748-53.

92. Belinchon MM, Gancedo JM. Xylose and some non-sugar carbon sources cause catabolite repression in Saccharomyces cerevisiae. Arch Microbiol. 2003;180(4):293-7.

93. Petersson A, Almeida JR, Modig T, Karhumaa K, Hahn-Hagerdal B, GorwaGrauslund MF, Liden G. A 5-hydroxymethyl furfural reducing enzyme encoded by the Saccharomyces cerevisiae ADH6 gene conveys HMF tolerance. Yeast. 2006;23(6):455-64.

94. Larroy C, Fernandez MR, Gonzalez E, Pares X, Biosca JA. Characterization of the Saccharomyces cerevisiae YMR318C (ADH6) gene product as a broad specificity NADPH-dependent alcohol dehydrogenase: relevance in aldehyde reduction. Biochem J. 2002;361(Pt 1):163-72.

\section{Publisher's Note}

Springer Nature remains neutral with regard to jurisdictional claims in published maps and institutional affiliations.
Ready to submit your research? Choose BMC and benefit from:

- fast, convenient online submission

- thorough peer review by experienced researchers in your field

- rapid publication on acceptance

- support for research data, including large and complex data types

- gold Open Access which fosters wider collaboration and increased citations

- maximum visibility for your research: over $100 \mathrm{M}$ website views per year

At BMC, research is always in progress.

Learn more biomedcentral.com/submissions 